\title{
The influence of chokeberry juice and inulin as osmotic-enriching agents in pre-treatment on polyphenols content and sensory quality of dried strawberries
}

\author{
Jolanta Kowalska ${ }^{1,3}$, Andrzej Lenart2,3, Sylwia Roszkowska ${ }^{1,3}$ and Hanna Kowalska ${ }^{2,3}$ \\ ${ }^{1}$ Department of Technology and Food Evaluation, Warsaw University of Life Sciences, \\ 159c Nowoursynowska St., 02-776 Warsaw, Poland \\ ${ }^{2}$ Department of Food Engineering and Process Management, Warsaw University of Life Sciences, \\ 159c Nowoursynowska St., 02-776 Warsaw, Poland \\ ${ }^{3}$ Institute of Food Sciences, Warsaw University of Life Sciences, 159c Nowoursynowska St., 02-776 Warsaw, Poland \\ e-mail: jolanta_kowalska@sggw.pl
}

\begin{abstract}
The objective of this study was to explain the effect of osmotic dehydration pre-treatment (chokeberry juice or inulin) and drying method (microwave-convective drying or freeze-drying) on polyphenols content, antioxidant activity and sensory properties of dried strawberries. The addition of a chokeberry juice concentrate to the osmotic solution significantly influenced the increase of polyphenols content in the fruit. Their content was significantly higher in the samples treated via osmotic dehydration in solutions containing the chokeberry juice concentrate, followed by freeze-drying and also by microwave-convective method. The ability to bind DPPH $\bullet$ radicals ranged from $40 \%$ in the dried strawberries without osmotic dehydration to $82 \%$ in fruit osmo-dehydrated in a mixture of inulin and the chokeberry juice concentrate and dried by freeze-drying. Study results indicate that the concentrated chokeberry juice and inulin can be used as beneficial osmotic substances. The dried strawberries can represent an alternative to snacks or may be attractive component of other products. One of the very attractive proposals for today's increasingly demanding consumers can therefore be dried fruit snacks enriched with natural bioactive ingredients.
\end{abstract}

Key words: osmotic dehydration, freeze-drying, microwave-convective drying, polyphenols, sensory properties

\section{Introduction}

Growing consumer awareness has recently been observed concerning the impact of nutrition on health and proper functioning of the body. It encourages food manufacturers to offer products that are not only safe but also provide health-promoting ingredients. Fruit constitute a source of natural bio-components. The use of strawberries in the food industry is caused by their taste as well as properties of their bioactive components (Del Bubba et al. 2016, Dermesonlouoglou et al. 2016). Due to the seasonal character of fruits and short period of their availability in the fresh form, these are getting frozen on a wide scale and consumed throughout the year after defrosting. However, this is not comfortable. The frozen fruit represent also industrial raw material to be processed into different products. In turn, dried fruit snacks occupy a special place on the food market as an alternative to high calorie chips. The possibility of enriching them with additional bio-components increases their attractiveness. Traditional drying used for fruit preservation adversely affects their quality and causes loss of labile ingredients. One of the treatments used to minimize defects of dried products is osmotic dehydration in sugar solutions used before drying (Aktas et al. 2013). In addition, this process shortens the drying time and increases dryer efficiency (Yadav and Vir Sing 2014). From a nutritional point of view, sugar added into the osmo-dehydrated product is not preferred and therefore it is advisable to replace it with other osmotic substances. An alternative in this case may be a fruit juice, e.g. chokeberry juice rich in natural antioxidants or inulin characterized by a low glycemic index and probiotic properties (González-Herrera et al. 2015, Kowalska et al. 2017). Chokeberry fruit is a rich source of vitamins and polyphenols, mainly anthocyanins, containing the largest amount of these compounds among all berries (Wilkes et al. 2014). The chokeberry fruit have a positive impact on human health, including e.g. anticarcinogenic effect, and reduce the risk of development of cardiovascular system diseases or diabetes (Jurikova et al. 2017).

Inulin is a polysaccharide listed among the GRAS (Generally Recognized As Safe) compounds. Due to such properties as a beneficial effect on the proper metabolic functions, it is used as a prebiotic, a substitute for fat and sugar, a texture modifier, and a functional nutrient (Shoaib et al. 2016). The composition, physicochemical and antioxidant properties, as well as the prevention effect of many diseases, it confirms the right choice of inulin and chokeberry fruit processed products (concentrated juice) as components of an osmotic solution (Khoo et al. 2017). The use of pre-osmotic dehydration (enrichment) with fruit juice concentrates makes it possible to modify properties of dried fruits, in particular their sensory properties, thereby influencing consumer preferences. The microwave - 
convective drying of strawberries can be alternative to freeze-drying method. It might bring many benefits, including improvement in dried fruit quality compare to traditional methods. Microwave drying requires a choice of adequate drying parameters for various fruits (Marzec et al. 2010). Texture and sensory properties are the most important quality attributes of food products.

The objective of this study was to analyze the effect of osmotic dehydration pre-treatment with a chokeberry juice concentrate and inulin as osmotic agents and two drying methods (freeze-drying and microwave-convective drying) on polyphenols content, antiradical activity, and also sensory properties of dried strawberries.

\section{Materials and methods}

\section{Materials}

In this study frozen strawberries of the Honeoye variety purchased from a producer were examined. The fruit had a diameter of $25-30 \mathrm{~mm}$. Cleaned and stemmed fruit was frozen in a chamber shock freezer (IRINOX S.P.A model 51.20) at a temperature of $-40{ }^{\circ} \mathrm{C}$ for 24 hours and stored at $-20^{\circ} \mathrm{C}$ for approximately one month.

\section{Osmotic dehydration}

For osmotic dehydration, the whole frozen fruit samples were only partly defrosted for 10 min to prevent leakage. The osmotic dehydration was carried out in $50 \%$ solutions of sucrose, inulin, and mixtures of sucrose with inulin $(1: 1 \mathrm{w} / \mathrm{w})$, sucrose with chokeberry juice concentrate $(1: 1 \mathrm{w} / \mathrm{w})$ as well as chokeberry juice concentrate with inulin (1:4 w/w). Sucrose was purchased in a local shop. Inulin ORAFTI - GR with 93\% of inulin in dry matter (purchased at Hortimex company, Poland) and chokeberry Aronia melanocarpa juice concentrate (purchased at RAUCH Poland) at $65^{\circ} \mathrm{Brix}$ were also used as osmotic substances. Fruit samples were dehydrated in each osmotic solution at a temperature of $50{ }^{\circ} \mathrm{C}$ for 60 minutes (Kowalska at el. 2017). The experiment was performed in triplicate.

\section{Drying}

Fresh (as control) and osmo-dehydrated samples were dried by microwave-convective drying at a temperature of $60{ }^{\circ} \mathrm{C}$ for 1 hour with an air velocity of $1.7 \mathrm{~m} \mathrm{~s}^{-1}$ using microwave power of $200 \mathrm{~W}$ in the laboratory microwaveconvection dryer PROMIS - mLAB ("PROMIS" Company, Wroclaw, Poland) or by freeze-drying at $25^{\circ} \mathrm{C}$ and pressure $63 \pm 0.1 \mathrm{~Pa}$, safety pressure $103 \mathrm{~Pa}$ for 24 hours. Before freeze-drying the strawberries were frozen at $-70^{\circ} \mathrm{C}$ for 2 hours in a Profi Master fridge (National Lab $\mathrm{GmbH}$ ).

\section{Chemical analyses}

The collected samples were analyzed to determine the dry matter content (AOAC 920.15, 2002), polyphenols content (Sluis et al. 2002), and antiradical activity against DPPH• (2,2- diphenyl-1-picrylhydrazyl radical) (Wu et al. 2007).

Dry matter content of each tested sample (fresh, osmo-dehydrated, and dried) was determined gravimetrically by vacuum drying (HORYZONT SPT 200, Poland) at $\leq 100 \mathrm{mmHg}$ and a temperature of $70^{\circ} \mathrm{C}$ until a constant weight has been achieved. The samples were weighed on an analytical scale with the accuracy of $0.001 \mathrm{~g}$.

The Folin-Ciocalteu reagent was used to determine the content of polyphenolic compounds (total polyphenols content) in fresh, osmotically dehydrated, and dried strawberries. Acetone extracts were prepared by adding 30 $\mathrm{cm}^{3}$ of $80 \%$ acetone to $1.0 \mathrm{~g}$ of fresh or to $0.2 \mathrm{~g}$ of dried strawberries. Distilled water was added to a set volume of the extract, followed by Folin-Ciocalteu reagent and sodium carbonate, and topped with distilled water. Absorbance measurements were performed with Hei入ios $\gamma$ ThermoSpectronic spectrophotometer at the wavelength of $750 \mathrm{~nm}$ against the blank sample. The standard curve was plotted for chlorogenic acid and based on various concentrations used in absorbance measurements. Based on this, the pholyphenols content was calculated in the samples, including dilution. Results were expressed as g gallic acid equivalents.100 g ${ }^{-1}$ d.m. (g GAE 100 g ${ }^{-1}$ d.m.).

The modified method proposed by Wu et al. (2007) was used to establish the antioxidant ability and DPPH• scavenging capability of strawberry extracts. The extracts were prepared analogously to determinations of polyphenols content. The basic DPPH• extract was prepared by dissolving $1.2 \mathrm{mg}$ of DPPH • in $50 \mathrm{~cm}^{3}$ of $99 \%$ methanol, from which the blank sample was prepared. The Heגios $\gamma$ ThermoSpectronic spectrometer was used for absorbance measurement at a wavelength of $515 \mathrm{~nm}$. The antioxidant activity of the analyzed extracts $(A)$ was recalculated 
based on absorbance results of the exact and control samples in He $\lambda$ ios $\psi$ ThermoSpectronic spectrometer at a wavelength of $515 \mathrm{~nm}$, against $99 \%$ methanolic extract.

The antioxidant activity of the strawberry extracts against DPPH• radicals was calculated based on results achieved for the control sample (absorbance of DPPH• solution) and exact samples (ability of the substance tested to inhibit oxidation reaction) and expressed in \%. The analyses of dry matter content, total polyphenolics content, and antiradical activity were carried out in five replicates.

\section{Sensory evaluation}

The sensory evaluation of osmo-dehydrated and dried strawberries was carried out using sensory descriptive analysis in accordance with the methodology described by Baryłko-Pikielna and Matuszewska (2014). Samples were coded by 2-digit random numbers and served to panelists in a random order. The evaluation was conducted by a trained 15-person team. The first stage of the assessment was to determine the distinguishing features and their definitions, and then to verify them. The intensity assessment scale was set from 0 to 10 with specific boundary conditions (Table 1).

Table. 1. Sensory descriptors and boundary conditions

\begin{tabular}{|c|c|c|c|}
\hline \multicolumn{2}{|c|}{ Sensory descriptors } & Boundary values from 0 to 10 & Definition \\
\hline \multicolumn{2}{|c|}{ Flavour } & Imperceptible - very intense & Characteristic of fresh strawberries \\
\hline \multicolumn{2}{|l|}{ Taste } & Imperceptible - very intense & characteristic for strawberries, from slightly sour to sweet \\
\hline \multirow{3}{*}{ 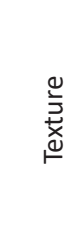 } & Hardness & Hard - soft & $\begin{array}{l}\text { Resistance the sample poses when biting - the force } \\
\text { needed to gnaw through the sample }\end{array}$ \\
\hline & Softness & Very soft, cohesive - a very hard, & $\begin{array}{l}\text { Softness as a rubberiness and cohesiveness as constituting } \\
\text { resistance when biting, non-cohesive }\end{array}$ \\
\hline & Crispness & Not crispy - very crisp, & $\begin{array}{l}\text { The sensation is felt and heard when biting the sample, } \\
\text { breaking under pressure }\end{array}$ \\
\hline \multicolumn{2}{|c|}{ Overall quality } & Unacceptable - acceptable & $\begin{array}{l}\text { General sensory impression including aroma, taste and } \\
\text { texture }\end{array}$ \\
\hline
\end{tabular}

Panelists randomly received individual samples of strawberries and marked the results with respect to specific descriptors on a scale. They were asked to express an overall quality evaluation as a subjective assessment of the tested samples, which is a combination of all unit features. Average values were calculated and presented in charts.

\section{Statistical analyses}

The statistical analysis of results was performed using Statistica 13.0 software based on one- and two-way analysis of variance at a significance level of $p=0.05$ to determine accordingly the effect of the osmotic solution on dry matter content of osmo-dehydrated samples and osmotic pre-treatment and of the two methods of drying on chemical and physical of dried strawberries. Significant differences between means were determined using the Tukey test. The principal component analysis (PCA) was performed to evaluate the dependence of the experimental result and to determine correlations between the selected sensory attributes.

\section{Results and discussion}

\section{Dry matter content in osmo-dehydrated and dried strawberries}

The type of the osmotic solution had no significant effect on dry matter content in strawberries osmo-dehydrated at temperature of $50{ }^{\circ} \mathrm{C}$ for 60 minutes (Fig. 1). In comparison to frozen strawberries with dry matter content at approximately $10.0 \%$, a stronger effect of osmotic dehydration was observed for the samples immersed in a sucrose solution (about 16.0\%). The least effective dry matter change was observed in the samples dehydrated in a mixture of inulin and chokeberry juice concentrate (about 12.0\%) and sucrose with chokeberry juice concentrate (about 12.5\%) (Fig. 1). Many literature sources have described various ranges of diffusion of osmotic substance particles as affected by their molecular weight (Kowalska et al. 2017, Dermesonlouoglou and Giannakourou 2018). Therefore, discrepancies between results might be due to the osmotic substances differing, among others, in their molecular weight. The results obtained indicate slightly higher content of dry matter in the samples dehydrated in the solutions containing sucrose. 
The research confirms the higher dry matter gain in strawberry tissue by the osmotic dehydration process. From the nutritional point of view, it is important to avoid sugar addition into food, which is very popular as an osmotic substance. A good alternative in this case is a fruit juice concentrate, e.g. from chokeberry fruit, which is rich in natural antioxidants or inulin as sugar with confirmed prebiotic potency.

The increase in the dry matter content as a result of the osmotic pre-treatment influenced the course of the drying process and the sensory properties of the final products. Initial osmotic dehydration allows obtaining high quality dried fruit as it was shown by Bruijn and Bórquez (2014) and Kowalska et al. (2018). Due to the lability of bioactive compounds of strawberries and chokeberry concentrate, a low temperature heat treatment was employed. However, all samples were characterized by a high content of dry matter (93.5-98.0\%). In the case of dried fruit, the statistical analysis indicated the lack of differences $(p>0.05)$ in the dry matter content depending on drying method. Similarly, there was no influence of osmotic solution applied in the pretreatment, regardless of drying method (Fig. 1). However some trends were observed. In most cases the dry matter content of freeze-dried strawberries (at $25^{\circ} \mathrm{C}$ for 24 hours) was higher by a few percentage points compare to strawberries dried by microwave-convective method (at $60^{\circ} \mathrm{C}$ for 1 hour) (Fig. 1). The higher (about 98.0\%) content of dry matter was noted in samples dehydrated in solution of inulin and chokeberry juice mixture, and then freeze-dried, whereas the lower one (about 93.5\%) in strawberries not osmo-dehydrated but only dried with the microwave-convective method. The microwave-convective drying of strawberries allowed obtaining dried samples in a shorter time with similar properties to the freeze-dried ones. The indicated differences may also result from the heterogeneity of the material as well as the operation of microwaves (Holtz et al. 2010) causing hot spots and overheating of the product (de Bruijn et al. 2016).

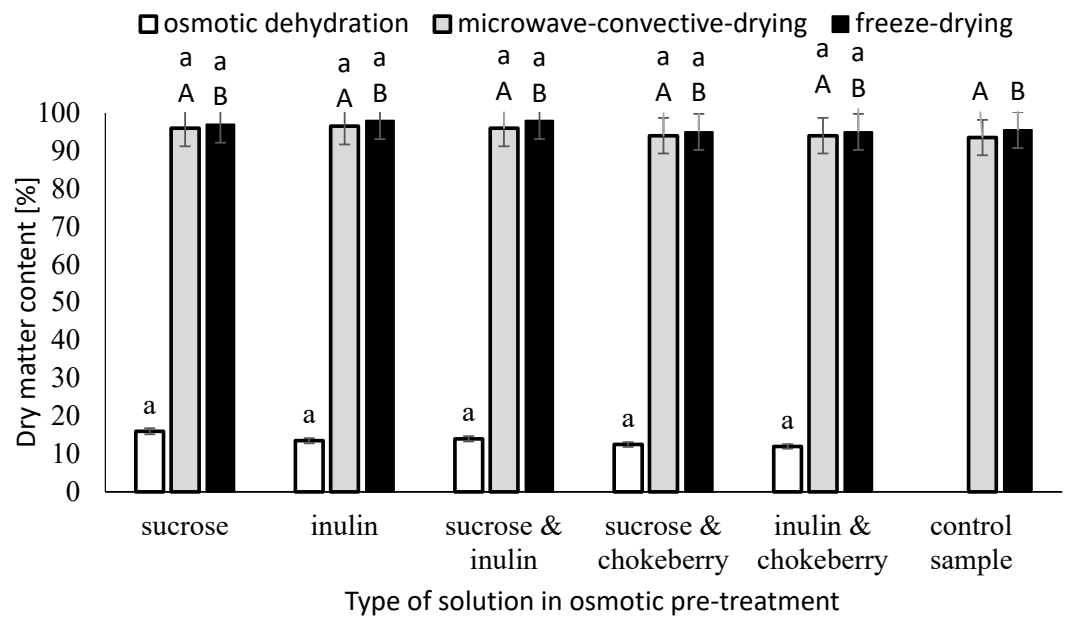

Fig. 1. The influence of osmotic solution and drying method on dry mater content in osmo-dehydrated and dried strawberries. Various letters in the columns show statistical difference among the results $(p<0.05) ; a, b$ concern the effect of type of osmotic solution used in pre-treatment and A, B - drying method

\section{The impact of using chokeberry juice concentrate and inulin as a natural osmotic agent on the chemical composition of strawberries}

Strawberries are rich source of natural antioxidants. The content of polyphenols in strawberries was around 5.7 g GAE $100 \mathrm{~g} \mathrm{~g}^{-1} \mathrm{~d}$.m. ents and corresponded with results reported by other researchers (Sun et al. 2014). The study conducted by Tulipani et al. (2008) and Kosińska et al. (2013) demonstrated various contents of polyphenolic compounds in strawberries, depending on their variety (from approx. 5.0 to more than $8.0 \mathrm{~g}$ GAE $100 \mathrm{~g}^{-1} \mathrm{~d} . \mathrm{m}$ ).

In the control samples (without pre-osmotic dehydration) the total polyphenols content was similar in fruit dried by both freeze-drying and microwave-convective method (approx. 4.5 and $5.0 \mathrm{~g} \mathrm{GAE} 100 \mathrm{~g}^{-1} \mathrm{~d}$.m., respectively).

The osmotic dehydration of strawberries facilitated an increase in the total polyphenols content, especially in the solution containing chokeberry concentrate. The statistical analysis confirmed significant effect of osmotic solution type onto total polyphenols content in osmo-dehydrated and dried strawberries. In the osmo-dehydrated samples, the highest content of total polyphenols was obtained in strawberries immersed in solutions containing chokeberry juice concentrate compared to the results concerning strawberries dehydrated in solutions containing sucrose or inulin (Fig. 2). 


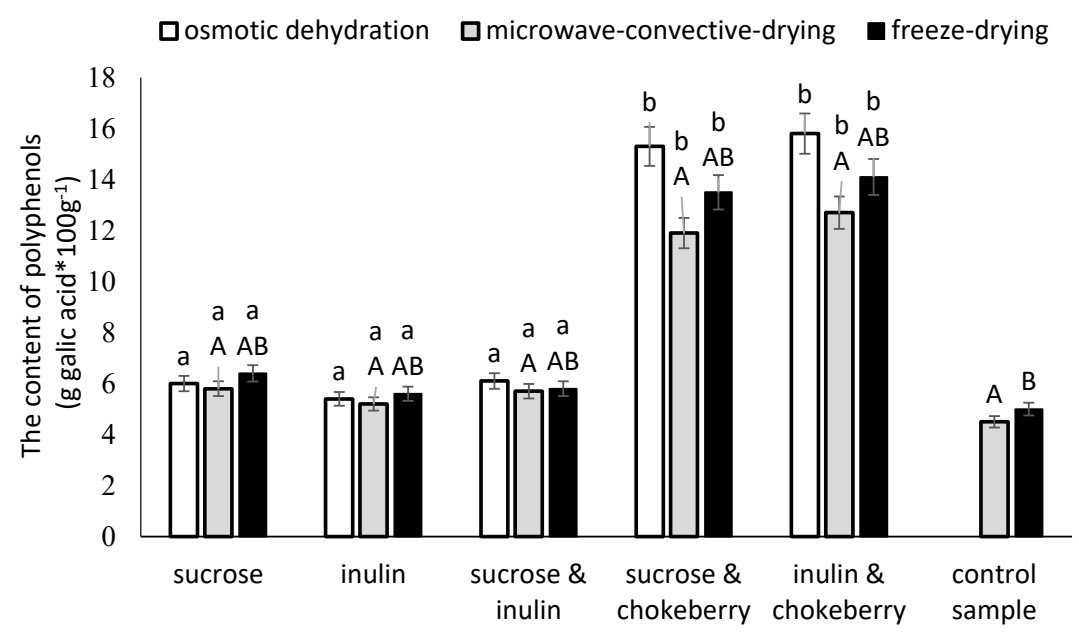

Type of solution in osmotic pre-treatment

Fig. 2. The influence of osmotic solution and drying method on the content of polyphenols in osmo-dehydrated and dried strawberries. Various letters in the columns show statistical difference among the results $(p<0.05) ; \mathrm{a}, \mathrm{b}$ concern the effect of type of osmotic solution used in pre-treatment and A, B - drying method

The type of osmotic solution had strong influence on the polyphenols content in the dried fruit (Fig. 2). However, their content was also affected by the drying method. The highest content of polyphenols was determined in samples dehydrated in solutions containing chokeberry juice concentrate (Fig. 2). These were separate homogeneous groups regardless of whether these were dried by freeze-drying or microwave-convective method. The content of polyphenols in strawberries dehydrated in the solution with the addition of chokeberry juice concentrate and dried was approximately 2-times higher as in case of these subjected to osmosis in other solutions.

The traditional drying process caused polyphenols losses due to the effects of temperature, oxygen, and light. Polyphenols undergo oxidative and hydrolytic modifications, and also are subject to concentration changes and transformation into complex tannins. Some antioxidant compounds degrade under thermal operations, especially labile anthocyanins (Korbel et al. 2013). Therefore, the total content of phenols may increase as reflected in the conducted studies. A smaller reduction was found in the freeze-dried samples (Fig. 2). This process was carried out at lower temperature $\left(25^{\circ} \mathrm{C}\right)$, moreover, polyphenol oxidase, taking part in the polyphenol oxidation process, could be inactivated in the pre-freezing process (Kowalska et al. 2017).

Similarly, in the study of Kowalska et al. (2017) the pre-osmotic treatment and drying caused degradation of polyphenols and anthocyanins in dried fruit. These authors tested apples dried by different methods and showed that polyphenols content was approximately $21 \%$ lower in the freeze-dried apples than in the fruit dried by the hybrid method (convective-microwave-vacuum drying).

Study results demonstrate that the microwave-convective drying had a slightly stronger influence on polyphenols degradation. It might have been caused by air as a drying agent in the process of convection and its impact on oxidative changes in polyphenols contained in the investigated samples. In addition, degradation of polyphenols depended on the temperature used. The temperature used in the microwave-convective drying was more than two times higher than in the freeze-drying method. Polyphenols degradation increased at temperature above $60^{\circ} \mathrm{C}$. It also depended on other factors, including the properties of processed material, water content, oxygen availability, etc. (Fang and Bhandari 2011). The impact of the high temperature on the content of polyphenols was examined by Fang and Bhandari (2011) and Nowacka and Witrowa-Rajchert (2010), who observed their degradation during the drying process.

Maintaining the balance between the amount of free radicals and the antioxidant system is particularly important for human health (Białek et al. 2012). In this study, the statistical analysis showed the effect of osmotic solution type and drying method on radicals activity (DPPH•) (Fig. 3). The ability to bind DPPH • radicals varied depending on the technological treatment and the type of osmotic solution ranged from $40 \%$ in strawberries dried with the microwave-convective method (without osmotic dehydration) to $84 \%$ in fruit dehydrated in the solutions containing chokeberry juice concentrate (Fig. 3). 


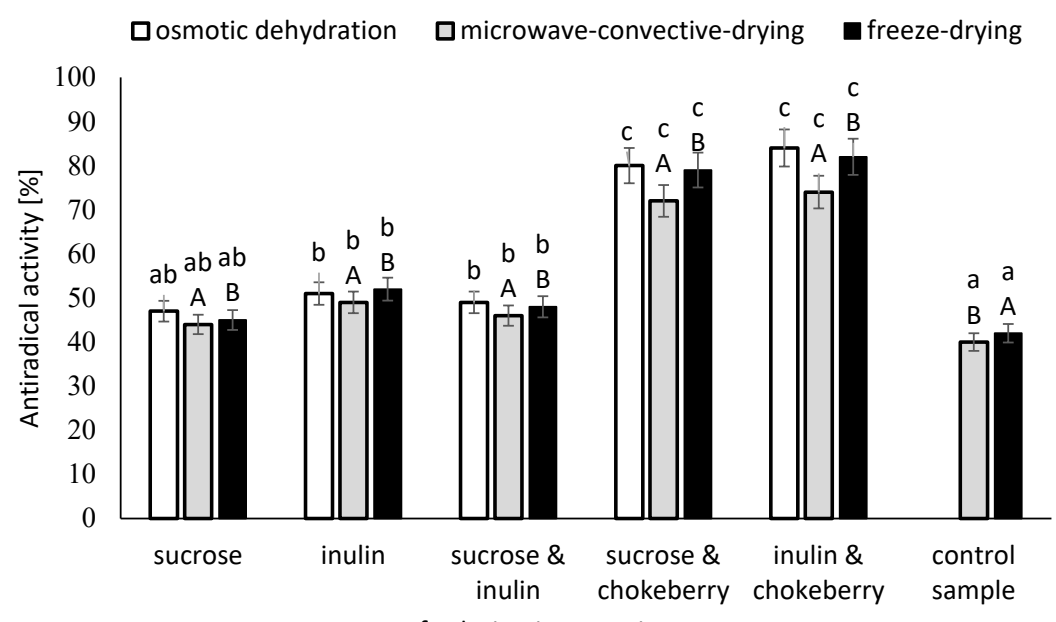

Fig. 3. The influence of osmotic solution and drying method on the antiradical activity in osmo-dehydrated and dried strawberries. Various letters in the columns show statistical difference among the results ( $p<0.05)$; a, b concern the effect of type of osmotic solution used in pre-treatment and A, B - drying method

The antiradical activity of dehydrated strawberries in a solution with addition of chokeberry concentrate was up to approximately $60 \%$ higher compared to the fruit dehydrated in other osmotic solutions. This might be due to high content of polyphenols in chokeberry fruit. The loss of water-soluble compounds, e.g. anthocyanins, was observed during osmotic dehydration of apples (Tulipani et al. 2008). The same conclusion was formulated by Jacob and Paliyath (2012) who tested blueberries and cherries. They showed that DPPH• radicals scavenging activity of fresh and osmo-dehydrated fruit did not differ significantly. This suggests that the antioxidant activity of dehydrated fruit is not disturbed by the process.

In most cases, there was a tendency towards higher antioxidant activity in strawberries osmo-dehydrated and subjected to freeze-drying compare to microwave-convective drying (Fig. 3). The research conducted by Szlachta and Małek (2008) showed the weakening of the antiradical activity in the products containing sucrose. It cannot unequivocally confirm the indicated thesis with respect to the current study, because strawberries dehydrated in the sucrose solution showed relatively high and similar to other samples antiradical activity. The result obtained in the presented study revealed significantly higher antiradical activity of the freeze-dried strawberries (Fig. 3) that were dehydrated in solutions containing chokeberry juice concentrate (mixture with inulin or sucrose). Samples dried by the microwave-convective method after osmotic dehydration in solutions with chokeberry juice exhibited by approximately $10 \%$ lower activity than the freeze-dried samples but approximately $5 \%$ higher activity than the control samples (non osmo-dehydrated). Moreover, there were relatively small differences in the tested parameters between the samples dehydrated in various solutions and also dried by the two methods, except the samples dehydrated in chokeberry juice concentrate. Despite the higher drying temperature $\left(60^{\circ} \mathrm{C}\right)$, the microwave-convective drying had strong impact on the antiradical activity. It was probably influenced by much shorter drying time (1h) compare to freeze-drying (24h). This has been confirmed by studies curried out by Xie et al. (2014).

The results obtained indicate feasibility of using the chokeberry juice concentrate as a osmotic agent, which enriches the product with polyphenols, and of using inulin as a natural prebiotic that stimulates the growth of beneficial intestinal microflora and improves the body's immunity. The dried fruit may constitute an alternative to snacks and may be added in the processing operations, e.g. as a fruity addition to yoghurt, cake or other desserts. The applied methods of drying at fixed parameters do not cause substantial degradation of antioxidants, which allows obtaining an attractive product not only from the sensory point of view but also containing bioactive components.

\section{Sensory evaluation}

Sensory results were grouped around quality indicators such as taste, flavor, crispness, hardness, softness and overall quality (Fig. 4 and 5). Fresh strawberry is characterized by sweet and slightly sour taste, depending on the variety and maturity. The sensory evaluation of fresh strawberries showed that such attributes as taste, flavor, softness, and overall quality were the highest (each with 10 points) (Fig. 4). The lowest scores were given by panelists to crispness and hardness. 
Osmotically dehydrated samples were rated lower, but very similar to fresh fruit.
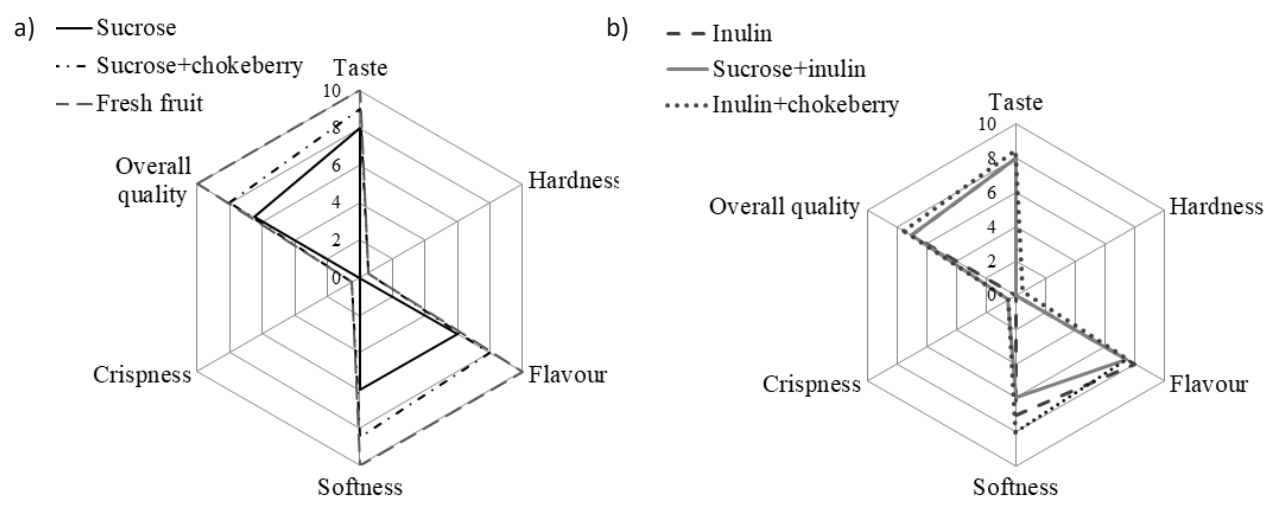

Fig. 4. The influence of osmotic solution on sensory properties of osmo-dehydrated strawberries

Based on the panelists' high taste ratings, it can be thought that slightly sweet and slightly acidic osmotic dehydrated samples in a mixture of sucrose and chokeberry juice concentrate are preferred. Their taste is due to the penetration of sucrose (sweet taste) and chokeberry concentrate (sour taste) solution. The high scores were given also for the analyzed sensory attributes to the samples dehydrated in mixture of sucrose and inulin solution, while the lowest ones to strawberries dehydrated in a sucrose solution. Individual indications were evaluated in a similar way by all panelists. Therefore, it is reasonable to consider the use of inulin and fruit juice concentrates, including chokeberry, as osmotic substances. Sensory properties of the dehydrated samples were acceptable.

The drying of osmo-dehydrated strawberries resulted in varied evaluations of sensory properties. The freeze-dried fruit obtained the highest scores for taste and crispness (Fig. 5).

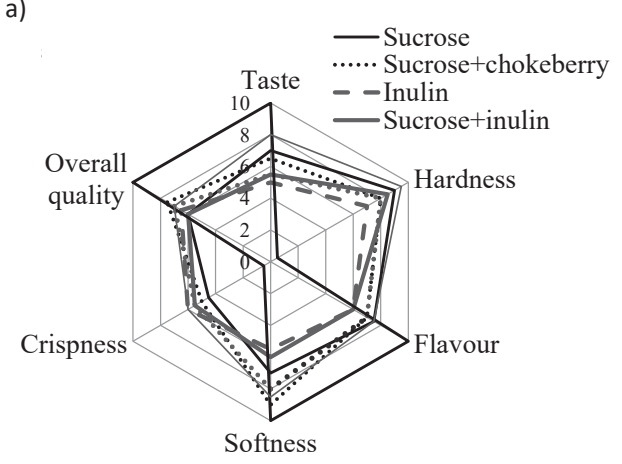

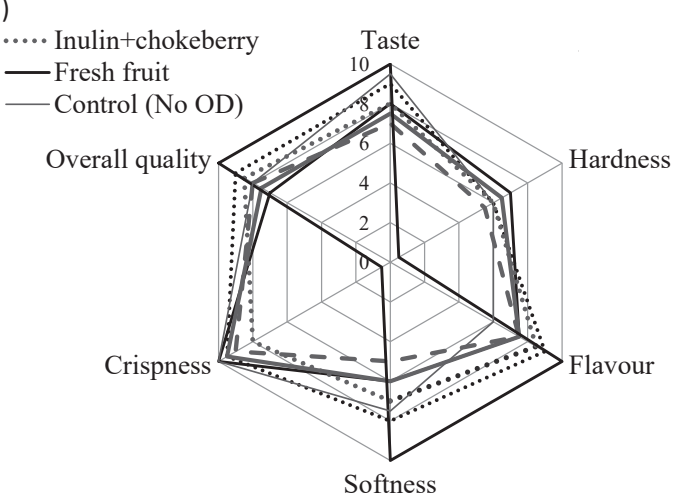

Fig. 5. The influence of osmotic solution and drying method on sensory properties of osmo-dehydrated strawberries and dried by a) microwave-convective, b) freeze-drying

High taste ratings of the samples may have been associated with features reminiscent of the taste of fresh fruit (Marzec et al. 2010).

Sensory team members gave high scores to freeze-dried strawberries for crispness, especially compared to the samples dried with the microwave-convective method. These features are highly valued in the case of dried snacks (Marzec et al. 2010). Highly scored was also the flavor of the freeze-dried strawberries, but except samples osmo-dehydrated with inulin participation. The relatively low temperature of drying is a natural protection for the flavor compounds, including these that enhance flavor. According to the panel evaluation, strawberries dried by microwave-convective method were characterized by more hardness and lower crispness.

In addition, the water loss caused higher concentration of dry matter, whereas the higher temperature during microwave-convective drying of strawberries could change their sensory properties. For example, fruit darkening was caused by osmotic dehydration in different solutions; this had an effect on the overall quality of the fruit. Samples of strawberries dried by microwave-convective method were very hard and required a high force when breaking or biting. This could be an undesirable and even disqualifying trait in the case of samples to be used as 
snacks. On the other hand, it may prove to be a positive feature when using dried fruit as a yoghurt ingredient. The higher notes for overall quality of dried samples were observed in the freeze-dried strawberries, particularly in these pre-dehydrated in the solution with chokeberry juice concentrate. The results of study of Colquhoun et al. (2012) indicate that sweetness and complex flavor are the most important attributes of strawberries, while perceived health benefits had little influence on consumer preference.

In order to determine the similarities and differences between the dried strawberry samples in the aspect of the evaluated chemical and sensory properties, the Principal Component Analysis (PCA) with classification was taken into account including the mean values of the results obtained for each of the tested indicator (Fig. 6).

a)

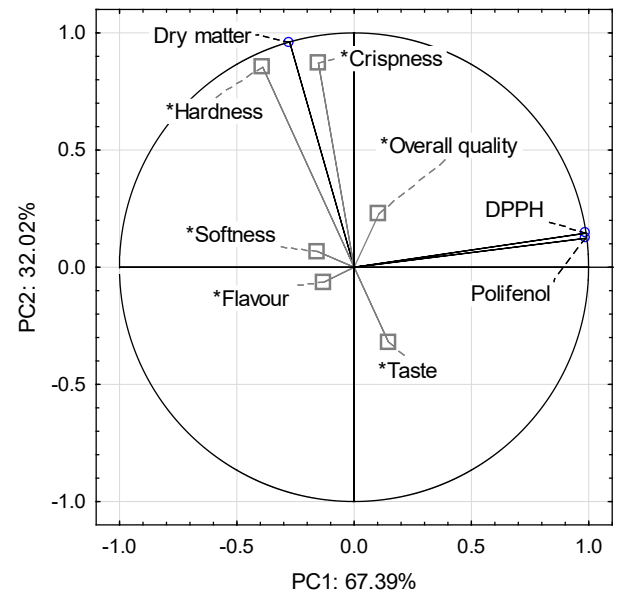

b)

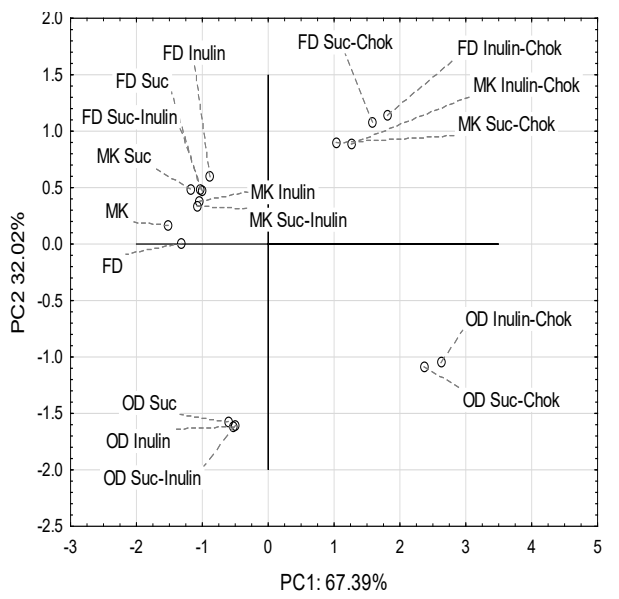

Fig. 6. Chemical and sensory properties of dried strawberries: a) diagram PCA, b) cases on the plane of factors. Coding markings: FD and MK - freeze-drying and microwave-convective drying; $\mathrm{OD}$ - osmotic dehydration; Suc, Inulin, Chok - type of osmotic solutions with sucrose, inulin and chokeberry juice concentrate

The number of tested variables was reduced to two principal components: PC1 (dry matter content, polyphenols content and antiradical activity) and PC2 (sensory attributes). The selected components (PC1 and PC2) explained $99.41 \%$ of the analyzed properties variability of the osmo-dehydrated and dried strawberries (Fig. 6a) with simultaneous $0.59 \%$ loss of information, respectively. In addition, all analyzed samples were characterized by a high antiradical activity, demonstrating ability to absorb and neutralize free radicals in the human body. In addition, there was a high positive correlation between total polyphenols content and antiradical activity against $\mathrm{DPPH} \bullet$. Many authors also showed a positive correlation between the antiradical activity demonstrated as ability to scavenge free DPPH • radicals and polyphenolics content (Incerti et al. 2009, Forbes-Hernandez et al. 2016, Dong et al. 2018). Other dependencies have been demonstrated by Al-Musharfi et al. (2015) who noted that despite the high content of polyphenols in fresh juices of six fruits, their antioxidant activity was not correlated with the polyphenolics content.

The common groups (high positive correlation marked by a dashed line; Fig. 6a) were also characterized by sensory characteristics such as flavor softness and also hardness and crispness with dry matter content of the samples. Another group (high negative correlation) consisted of hardness, crispness and dry matter content in combination with taste. According to Pearson's correlation matrix, the overall quality was significantly dependent on sensory impressions of dried fruits taste and flavor.

The PCA analysis revealed four or five groups (A-D) of osmo-dehydrated and dried strawberries with different polyphenols content or their activity and sensory properties depending on the type of osmotic solutions used in osmotic pre-treatment and methods of drying (Fig. 6b). It was observed that the osmotically dehydrated samples differed from the dried ones, including the initial osmotic treatment; they were two separate groups ( $A-B$ and C-D). Within group $A$, a subgroup of dried fruits as a result of osmotic dehydration in sucrose and inulin solutions, dried using both the microwave-convective and freeze-drying (A1) methods and control samples (A2) was distinguished. These two separate groups were both samples osmotically dehydrated in solutions containing chokeberry juice concentrate (D group) as well as dried fruits pre-treated with this osmotic solution component (B group). 


\section{Conclusion}

Fruit juice concentrate, e.g. from chokeberry which is rich in natural antioxidants or inulin with confirmed prebiotic attributes, is a good alternative to sucrose as an osmotic agent. The freeze-drying of strawberries previously subjected to osmotic dehydration revealed only a slightly higher polyphenols content and the ability to bind DPPH• radicals than these dried using microwave-convective method. The indicated differences may be due to the application of lower drying temperature in the case of freeze-drying and uneven microwave heating (local overheating), which affects the behavior of bioactive components.

The sensory evaluation confirmed feasibility of using inulin as a prebiotic and chokeberry juice concentrate rich in natural antioxidants as an osmotic substance. The use of freeze-drying and microwave-convective drying allows producing sensory acceptable fruit with only a slightly higher preference for freeze-dried fruit.

The dried strawberries are a source of natural antioxidants with a high antiradical activity and can be an alternative to snacks or may be an attractive component in other products.

\section{Acknowledgements}

This work was financially supported by SUSFOOD ERA-Net / NCBiR (National Centre for Research and Development); project no 5/SH/SUSFOOD1/2014. Implementation period: 2014-2017, Poland. The work was also co-financed by a statutory activity subsidy from the Polish Ministry of Science and Higher Education for the Faculty of Food Sciences of Warsaw University of Life Sciences.

\section{References}

Aktas, T., Ulger, P., Daglioglu, F. \& Hasturk, F. 2013. Changes of nutritional and physical quality characteristics during storage of osmotic pretreated apple before hot air drying and sensory evaluation. Journal of Food Quality 36: 411-425. https://doi. org/10.1111/jfq.12062

Al-Musharfi, N.K., Al-Wahaibi, H.S. \& Khan, S.A. 2015. Comparison of ascorbic acid, total phenolic content and antioxidant activities of fresh juices of six fruits grown in Oman. Journal of Food Process and Technology 6: 11 p. https://doi.org/10.4172/21577110.1000513

Baryłko-Pikielna, N. \& Matuszewska, I. 2014. Food sensory testing. Fundamentals - Methodologies - Uses. Krakow: Scientific Publisher PTTŻ. (in Polish).

Białek, M., Rutkowska, J. \& Hallmann, E. 2012. Black-necked aronia (Aronia melanocarpa) as a potential ingredient of functional food. Food. Science. Technology. Quality. (Żywność. Nauka. Technologia. Jakość.) 6: 21-30. (in Polish). https://doi.org/10.15193/ zntj/2012/85/021-030

Colquhoun, T.A., Levin, L.A, Moskowitz, H.R., Whitaker, V.M., Clark, D.G. \& Folta, K.M. 2012. Framing the perfect strawberry: An exercise in consumer - assisted selection on fruit crops. Journal of Berry Research 2: 45-61. https://doi.org/10.3233/JBR-2011-027

de Bruijn, J. \& Bórquez, R. 2014. Quality retention in strawberries dried by emerging dehydration methods. Food Research International 63: 42-48. https://doi.org/10.1016/j.foodres.2014.03.029

de Bruijn, J., Rivas, F., Rodriguez, Y., Loyola, C., Flores, A., Melin, P. \& Borquez, R. 2016. Effect of vacuum microwave drying on the quality and storage stability of strawberries. Journal of Food Processing and Preservation 40: 1104-1115. https://doi.org/10.1111/ jfpp.12691

Del Bubba, M., Giordani, E., Ancillotti, C., Petrucci, W., Ciofi, L., Morelli, D., Marinelli, C., Checchini, L. \& Furlanetto, S. 2016. Morphological, nutraceutical and sensorial properties of cultivated Fragaria vesca L. berries: influence of genotype, plant age, fertilization treatment on the overall fruit quality. Agricultural and Food Science 25: 187-201. https://doi.org/10.23986/afsci.56867

Dermesonlouoglou, E.K. \& Giannakourou, M.C. 2018. Evaluation and modelling of osmotic pre-treatment of peach using alternative agents in a multiple-component solution. Journal of the Science of Food and Agriculture 99: 1240-1249. https://doi. org/10.1002/jsfa.9296

Dermesonlouoglou, E.K., Giannakourou, M. \& Taoukis, P.S. 2016. Kinetic study of the effect of the osmotic dehydration pre-treatment with alternative osmotic solutes to the shelf life of frozen strawberry. Food Bioproducts Processing 99: 212-221. https:// doi.org/10.1016/j.fbp.2016.05.006

Dong, W., Cheng, K., Hu, R., Chu, Z., Zhao, J. \& Long, Y. 2018. Effect of microwave vacuum drying on the drying characteristics, color, microstructure, and antioxidant activity of green coffee beans). Molecules 23: E1146. https://doi.org/10.3390/molecules23051146

Fang, Z. \& Bhandari, B. 2011. Effect of spray drying and storage on the stability of bayberry polyphenols. Food Chemistry 129 : 1139-1147. https://doi.org/10.1016/j.foodchem.2011.05.093

Forbes-Hernandez, T.Y., Gasparrini, M., Afrin, S., Bompadre, S., Mezzetti, B., Quiles, J.L., Giampieri, F. \& Battino, M. 2016. The healthy effects of strawberry polyphenols: which strategy behind antioxidant capacity? Critical Reviews in Food Science and Nutrition 1: 46-59. https://doi.org/10.1080/10408398.2015.1051919 
González-Herrera, S.M., Herrera, R.R., López, M.G., Rutiaga, O.M., Aguilar, C.N., Contreras, E.J.C. \& Ochoa, M.L.A. 2015. Inulin in food products: prebiotic and functional ingredient. British Food Journal 117: 371-387. https://doi.org/10.1108/BFJ-09-2013-0238

Holtz, E., Ahrné, L., Rittenauer, M. \& Rasmuson, A. 2010. Influence of dielectric and sorption properties on drying behaviour and energy efficiency during microwave convective drying of selected food and non - food inorganic materials. Journal of Food Engineering 97: 144-53. https://doi.org/10.1016/j.jfoodeng.2009.10.003

Incerti, A., Navari-Izzo, F., Pardossi, A. \& Izzo, R. 2009. Seasonal variations in polyphenols and lipoic acid in fruits of tomato irrigated with sea water. Journal of the Science of Food and Agriculture 89: 1326-1331. https://doi.org/10.1002/jsfa.3589

Jacob, J.K. \& Paliyath, G. 2012. Infusion of fruits with nutraceuticals and health regulatory components for enhanced functionality. Food Research International 45: 93-102. https://doi.org/10.1016/j.foodres.2011.10.017

Jurikova, T., Mlcek, J., Skrovankova, S., Sumczynski, D., Sochor, J., Hlavacova, I., Snopek, L. \& Orsavova, J. 2017. Fruits of black chokeberry aronia melanocarpa in the prevention of chronic diseases. Molecules 22: 944. https://doi.org/10.3390/molecules22060944

Khoo, H.E., Azlan, A., Tang, S.T. \& Lim, S.M. 2017. Anthocyanidins and anthocyanins: colored pigments as food, pharmaceutical ingredients, and the potential health benefits. Food \& Nutrition Research 61: 1361779. https://doi.org/10.1080/16546628.201 7.1361779

Korbel, E., Servent, A., Billaud, C. \& Brat, P. 2013. Heat Inactivation of polyphenol oxidase and peroxidase as a function of water activity: a case study of mango drying. Drying Technology 31: 1675-1680. https://doi.org/10.1080/07373937.2013.808659

Kosińska, A., Diering, S., Prim, D., Héritier, J. \& Andlauer, W. 2013. Phenolic compounds profile of strawberry fruits of Charlotte cultivar. Journal of Berry Research 3: 15-23. https://doi.org/10.3233/JBR-130043

Kowalska, H., Marzec, A., Kowalska, J., Ciurzyńska, A., Czajkowska, K., Cichowska, J., Rybak, K. \& Lenart, A. 2017. Osmotic dehydration of Honeoye strawberries in solutions enriched with natural bioactive molecules. LWT-Food Science and Technology 85: 500-505. https://doi.org/10.1016/j.Iwt.2017.03.044

Kowalska, H., Marzec, A., Kowalska, J., Ciurzyńska, A., Samborska K., Bialik, M. \& Lenart, A. 2018. Rehydration properties of hybrid method dried fruit enriched by natural components. International. Agrophysics 32: 175-182. https://doi.org/10.1515/intag-2016-0100

Marzec, A., Kowalska, H. \& Zadrożna, M. 2010. Analysis of instrumental and sensory texture attributes of microwave-convective dried apples. Journal of Texture Studies 41: p. 417-439. https://doi.org/10.1111/j.1745-4603.2010.00234.x

Nowacka, M. \& Witrowa-Rajchert, D. 2010. Changes of radical scavenging activity, polyphenols content and colour during storage of infrared - convective dried apples. Acta Agrophysica 16: 391-400.

Shoaib, M., Shehzad, A., Omar, M., Rakha, A., Raza, H., Sharif, H.R, Shakeel, A., Ansari, A. \& Niazi, S. 2016. Inulin: Properties, health benefits and food applications. Carbohydrate Polymers 147: 444-54. https://doi.org/10.1016/j.carbpol.2016.04.020

Sluis, A., Dekker, M., Skrede, G. \& Jongen, W. 2002. Activity and concentration of polyphenolic antioxidants in apple juice. Effect of existing production methods. Journal of Agricultural and Food Chemistry 50: 7211-7214.https://doi.org/10.1021/jf020115h

Sun, J., Liu, X., Yang, T., Slovin, J. \& Chen, P. 2014. Profiling polyphenols of two diploid strawberry (Fragaria vesca) inbred lines using UHPLC-HRMSn. Food Chemistry 146: 289-298. https://doi.org/10.1016/j.foodchem.2013.08.089

Szlachta, M. \& Małek, M. 2008. Antioxidant properties of fruit teas. Food. Science. Technology. Quality. (Żywność. Nauka. Technologia. Jakość.) 1: 92-102. (in Polish).

Tulipani, S., Mezzetti, B., Capocasa, F., Bompadr, S., Beekwilder, J., Ric de Vos, C.H., Capanoglu, E., Bovy, A. \& Battino, M. 2008. Antioxidants, phenolic compounds, and nutritional quality of different strawberry genotypes. Journal of Agricultural and Food Chemistry 56: 696-704. https://doi.org/10.1021/jf0719959

Wilkes, K., Howard, L.R., Brownmiller, C. \& Prior, R.L. 2014. Changes in chokeberry (Aronia melanocarpa L.) polyphenols during juice processing and storage. Journal of Agricultural and Food Chemistry 62: 4018-4025. https://doi.org/10.1021/jf404281n

Wu, C., Huang, M., Lin, Y., Ju, H. \& Ching, H. 2007. Antioxidant properties of Cortex fraxini and its simple coumarins. Food Chemistry 104: 1464-1471. https://doi.org/10.1016/j.foodchem.2007.02.023

Xie, Z., Fan, J., Charlebois, D., Roussel, D., Dubé, C., Charles, M.T. \& Khanizadeh, S. 2014. Agronomic characteristics and phytochemical profiles of advanced June-bearing strawberry lines for the northern Canadian climate. Agricultural and Food Science 23: 38-47. https://doi.org/10.23986/afsci.8431

Yadav, A.K \& Vir Singh, S. 2014. Osmotic dehydration of fruits and vegetables: A review. Journal of Food Science and Technology 51: 1654-1673. https://doi.org/10.1007/s13197-012-0659-2 